\title{
Social Work and Diversional Therapy: Common Threads from a Strengths Perspective
}

\author{
Margaret Helmer ${ }^{1, *}$, Venkat Pulla ${ }^{2}$, Elizabeth Carter $^{3}$ \\ ${ }^{1}$ Charles Sturt University, Wagga Wagga, NSW, Australia \\ ${ }^{2}$ Social Work Discipline, Australian Catholic University, Brisbane, Australia \\ ${ }^{3}$ Australian Catholic University, Brisbane, Australia \\ *Corresponding Author: helmarg1@bigpond.com
}

\begin{abstract}
This paper seeks to explore the commonalities that exist within the professions of Diversional Therapy and Social work practice from a Strengths perspective. Highlighting the significance of social connectivity in the company of purposeful and meaningful engagement. Discussing therapeutic mechanisms, like Art therapy, which are commonly employed by both Diversional Therapists and Social Workers for restorative purpose.
\end{abstract}

Keywords Strength Based Practice, Diversional Therapy, Social Work, Resilience, Empowerment, Social Inclusion, Strengths Approach

\section{Introduction}

Human well-being is central to both Social work and Diversional therapy as they work collaboratively to alleviate human suffering. The Strengths Approach is embraced by both professions as it seeks to focus on the client's resources to aid their recovery (Wartel, 2003). The Strengths perspective cultivates resilience by empowering clients to focus on their present well-being as opposed to past difficulties (Wartel, 2003). Both professions seek to capitalise on the client's ability to survive by mobilising the client's strengths to achieve resilience (Wartel, 2003). In the same way, Social Work and Diversional Therapists motivate the client towards positive change. Recognising that positive thought patterns create feelings of well-being that challenges other negative beliefs (Wartel, 2003)

In Australia, Diversional therapy is a relatively new discipline that articulates the importance of social interaction, with the engagement of person-centred, purposeful living, which is the right of all people. It works to enhance the spiritual, emotional and psychosocial needs of persons who are at risk of social and emotional disengagement. "Diversional Therapy Australia's Mission is to ensure that the practice of Diversional Therapy continues to be viable and relevant contributing to the wellbeing of clients and the community" (Diversional Therapy Australia, 2014). Diversional therapists assist vulnerable people across the life-span in many sectors such as mental health, palliative care, disability, youth and aged care. Diversional therapy is a person-centred and restorative practice that respects and appreciates the importance of human dignity, imagination and creativeness. Diversional therapy facilitates recreational and leisure experiences that seek to enhance an individual's physical, cultural, psychological, social and emotional well-being. Commonly Diversional therapists find themselves undertaking similar tasks to that of Social Workers depending on the organisations they work. For example, a Diversional therapist employed in local government may have dual roles within a multi-disciplinary team that may include intake, assessment, advocacy, and referral.

Social workers support people who may be experiencing situational crisis or those who are socially, economically or culturally disadvantaged within society. Social Work assists, supports, connects, advocates for and empowers people at risk by using a range of support mechanisms such as counselling, information and community linkages to bring about change. Social work is caring, respectful, socially responsible and reflective. Social work seeks to improve the human condition, to alleviate pain and suffering by preserving the rights of others from a social justice framework; (Francis, Pulla, Clark, Mariscal, \& Ponnuswami, 2014). Social work adheres to the principles of social justice, to respect and to preserve the rights and dignity of people. Social work engages people and social structures to challenge oppression and to enhance the wellbeing of people (Australian Association of Social Workers, 2014).(AASW)

The professions of Social work and Diversional therapy work in harmony together to uphold the rights and dignity of vulnerable people underpinned by a social justice framework. A social justice framework reflects the principles of the egalitarian distribution of societal goods, prescribed rights and freedoms. Including opportunities and income which aim to reduce the incidences of inequalities, pertaining to health, social mobility, social exclusion or income inequality 
caused by globalisation (Crow,2007 \& Noonan,2011).

The Social workers and Diversional therapists role are to manage the multiplicity of their clients circumstances (Chenoweth \& McAuliffe, 2012). Diversional therapy and Social work embrace a reflexive methodology to improve the quality of practice by engaging in critical reflection that plans, acts, observes and reflects on Social work and Diversional therapy interventions (Chenoweth \& McAuliffe,2012). Both professional methodologies draw from a Strengths-based framework that focuses on the well-being and hope of recovery for vulnerable persons (Francis, et.al,2014). The Strengths perspective is especially suitable in explaining how these two professions work cooperatively as the perspective is greatly removed from the process of identifying pathology or deficiencies. The focus is what the client can do, correspondingly the client is not defined by deficit or disease (Francis, et.al,2014).To define clients by their strengths as opposed to their weaknesses is restorative, and instils hope for the future (Francis, et.al,2014).

Similarly, Social workers and Diversional therapists engage in person-centered restorative practices that seek to broaden human potential and enhance well-being (AASW,2013). Both professions value and recognise the client as the expert as they seek to empower the client via therapeutic facilitation to build hope for recovery. Both professions mutually reveal the "Strengths approach" by actively engaging the process of capacity building, along with compassion and empathy for clients (Francis, et.al,2014).

\section{Methodology}

This paper attempts to weave through commonality of the professional approaches of Social work and Diversional therapy by highlighting the interconnectedness of both approaches. This includes an attempt to validate the theoretical stance of Strengths-based practice (SBT), which focuses on the abilities of individuals, families and organisations, supported within the ethnographical accounts of their clients' experiences (Pulla, 2012). The approach to this analysis of commonality is predominately qualitative, anchored in grounded theory deduced from specific experiences with comparative observations of human behaviour as revealed in the Social Work and Diversional therapy practice contexts, to discover how people experience life. The paper will review the literature on strength-based practice and art therapy concluding with a discussion on commonality in Diversional therapy and social work.

\section{Literature}

Diversional therapy Australia, the body representing Diversional therapists in Australia, defines Diversional therapy as a tool that assists in shaping the environment for the comfort of others. Its role is to recognise and facilitate positive leisure opportunities which contribute to health and well-being as well as the enhancement of life quality. Diversional therapy accepts, encourages and provides an opportunity for fun and friendship via meaningful social engagement; to meet the social and emotional needs of clients by means of recreational and leisure activities (Diversional Therapy Australia, 2014)

Diversional therapists seek to enhance the social functioning of clients and reduce the incidence of depression, stress and anxiety by building on an individual's capacity for self-confidence and self-determination. Enhancing social functioning consequently can lead to improvements in an individual's quality of life. Diversional therapy activities are purposefully designed to promote health and wellness by limiting restrictions to social participation caused by illness, disability or cognitive impairment (Buettner \& Legg,2011). The intention is to overcome barriers and help maintain the physical, mental and emotional well-being of clients by seeking to reduce depression, stress and anxiety; recover basic motor functioning and reasoning abilities; build confidence, and socialise effectively. According to Buettner \& Legg, (2011) Diversional therapy acts positively on the quality of care including the quality of life for residents living in nursing homes. Hence, managers of facilities are encouraged to use recreational therapists to their fullest potential to improve the bio, psycho-social functioning of the client (Buettner \& Legg, 2011).

The professions of Social Work and Diversional therapy from a "Strengths-based approach", highlights the importance of acknowledging strengths and capacities. As well as integrating the principles of social justice, inclusion, self-determination and respect with a mutual regard for human rights (Francis, et.al,2014). It is in this way that Social work and Diversional therapy complement each other, as both professions seek to understand and meet the needs of clients by facilitating well-being that is respectful and socially just. The framework for Strength-based practice focuses on the respect and dignity of people with the right to govern their lives by employing their strengths, capabilities and resources to overcome adversity (Pulla, 2012). Strengths-based practice communicates hope for the future by encouraging social change thus opposing the dominant social structures that seek to oppress vulnerable people (Pulla, 2012). It gives credence to the belief that individuals can promote their recovery by drawing from personal strengths to aid resilience (Riggs \& Pulla, 2014).

Viewed in the context of social isolation, the authors contend that many clients have a sense of "otherness" that comes from social withdrawal. We recognise that this may relate to the psychological self, the emotional self, the physical self or the environment. The power of a Strengths perspective is optimism as it magically works to improve the quality of the client's lives by focusing on strengths as opposed to deficits (Healy,2005). Many clients of Social work and Diversional therapy live with depleted cultural and 
social capital. Due to factors that may be out of their control such as financial constraints limited education or physical or psychological illness (Chenoweth \& McAuliffe,2008).These clients have a reduced capacity to master their environment as limited autonomy prevails in their otherwise "governed" lives. With limited choices, their decision making is also undetermined or virtually nonexistent. Social work is the ability to assist those to help themselves by providing an opportunity for coping and resilience; within a respectful, culturally sensitive and supportive partnership that enables the client to seek positive change.

Strength-based practice is not about merely reframing clients thinking to find good in the situation, re-labelling weaknesses as strengths, ignoring that serious symptoms and problems exist and continue to exist, or compiling a list of strengths, it is about finding strengths alone that we hold even during critical moments and crises (Pulla,2012). Strength-based methodologies focus on what is working well, highlighting successful strategies, while issues are not ignored but defined and prioritised. This approach "focuses on identifying, mobilizing, and honouring the resources, assets, wisdom and knowledge that every person, family, group, or community has and leads to a rediscovery of these resources" (Pulla, 2012). Clients have experiences, abilities, knowledge and external support systems that assist them to move on in life. Using a strength-based approach allows the client, supported by the Social worker or Diversional therapist, to identify and build on strengths so that the client can reach goals and retain or regain independence in daily life. Practitioner observations have seen the approach improve self-care abilities, build confidence and self-esteem, and become independent in daily living activities (Pulla, 2012).

In opposition to negative assumptions, a strengths-based approach, focus is the inner strength of individuals to become resilient by way of positive adaptations coupled with enhanced coping mechanisms (Pulla, 2012,). Thus, a social worker may make a referral for a client with Multiple Sclerosis to participate within a recreational program to reduce social isolation and depression. Consequently, the Diversional therapist will assist this client to focus on positive leisure interests to holistically support his or her health or well-being.

Diversional therapists facilitate therapeutic processes to engage vulnerable clients intentionally in therapeutic activities, proven to reduce social isolation and emotional stress. Persons with Dementia may be affected by psychosocial outcomes predictably resultant from stress. Symptoms exacerbated by Dementia include resultant anxiety and depression, that impact on life quality, health and well-being (Dawson, Powers, Krestar, Yarry \& Judge,2013). Person's affected by dementia fight to retain their personhood, endeavouring to preserve health plus quality of life via relationships that evoke positive coping mechanisms mirroring a person-centred strengths-based perspective (Dawson, et al.,2013).

In the practice context, observations have been made noting that persons with dementia can have success when engaged in an activity that they enjoy. People with aphasia can remember the words to a song when they hear the music or discuss their artwork when wholly engaged within an activity (Dowling, 1995). Creativity and enjoyment may be the key to unlocking the inner spirit. Happiness is a felt emotion, people with dementia still have feelings and enjoy participating with others as they always did (Morris-Kay, 2010).

Strength-based practice is collaboration between the client and the social worker or facilitator; it helps clients to tell their stories or lived experiences in an interactive environment that is adaptive. The Strengths approach assists vulnerable clients to recognise and change negative narratives by exploring and acknowledging alternative narratives (Walther \& Fox, 2012) Demonstrating how a Social worker or Diversional therapist seeks to liberate the visions and hopes of vulnerable clients in a process of reconstruction (Riggs \& Pulla, 2014).

According to Dr Pachana studies indicate high protective factors via the provision of activities plus the level of partition including the maintenance of social networks linked to successful ageing (Ford,2005). Social interaction is the key to maintaining optimal health and is correlated to greater optimism including more positive self-evaluations with well-developed coping mechanisms proffering increased resilience (Ford, 2005). Social work in partnership with Diversional therapy has challenged the assumptions that aged persons will inevitably become socially disconnected. Arguing that life transitions may be troubled by identify or role confusion; however with perceived changes to societal consciousness older persons will gravitate towards increased social network connectedness to achieve successful ageing (Cornwell, Laumann \& Schumm, 2008).

Social Inclusion has been highlighted as integral to maximising the health and wellness for older adults including those who have dementia. As a consequence community-engaged art programs have been endorsing art as a means to support social connectivity. Correspondingly Social Workers and Diversional Therapists are often responsible for the administration and delivery of community-engaged art programs (Moody \& Phinney,2012).

The use of therapeutic arts is that it becomes a mechanism for self-expression that is very helpful to people with Dementia who may have lost their usual channels of communication. Therapeutic interventions such as art therapy have assisted some individuals to slow the process of dementia via adaptations to maintain their sense of self (Dowling, 1995). According to Dowling, (1995) the process of painting is extremely engaging, resulting in elevated mood with increased opportunities for reminiscence.

The arts frequently provide a medium for both Social work practice and Diversional therapy within the community that may assist vulnerable persons to achieve their goals. Diversional therapists often develop or facilitate arts-based programs that are complimentary to the goals and theoretical frameworks of Social work (Riggs \& Pulla, 2014). Art 
therapy has a place in community work that assists clients to alleviate some of the psychosocial stressors associated with socially isolated persons or those with debilitating illnesses such as dementia. Diversional therapists with a sensitivity for the arts may engage in art therapy without being deemed artists in their own right. Importantly, it is about the process of engagement and not the quality of the art itself Riggs \& Pulla, 2014). A Diversional therapist will positively, facilitate, motivate and therapeutically engage clients within a group activity to purposefully empower the clients by focusing on strengths to aid recovery (Pulla,2012).

\section{Discussion}

Social workers and Diversional therapists work collaboratively for the common beneficence of individual's well-being, by working with people in their environments to encourage and facilitate motivation for change. Fossey, Harvey, Mokhtari \& Meadows (2012 ) explored perceived needs and the barriers to meeting these perceived needs within a mental health context by investigating the links between perceived met needs and improved quality of life for the client. Relationships were discussed regarding medications, treatment or alternative options such as a talk-related therapies, counselling, social interaction or assistance with practical skills for example finances or social housing (Fossey, et.al, 2012). The findings of this qualitative research indicated that the perceived need for social interaction, friendship, companionship, leisure needs, counselling, information and medication were rated much higher than finance, housing, work skills, or domestic skills (Fossey, et.al,2012).

This paper endorses the principles of strengths-based practices by identifying the duality of purpose for both Social Work and Diversional therapy interventions. The framework for Strength-based practice focuses on the respect and dignity of people with the right to govern their lives by employing their strengths, capabilities and resources to overcome adversity (Pulla, 2012). Strengths-based practice communicates hope for the future by encouraging social change thus opposing the dominant social structures that seek to oppress vulnerable people (Pulla,2012). Reflecting a Strengths perspective Social workers and Diversional therapists would seek to support clients by focusing on what they can do and not what they can't do (Pulla,2012).

A Diversional therapist would seek to provide the client with dementia with a no-fail activity such as knitting as this skill has been committed to long-term memory. As long term skills can be conducted automatically without the necessity to learn a new skill thus validating the strengths of the clients (Dowling,1995). Such an activity may assist the client to fit in a social group setting as they can participate fully as dementia doesn't define them. A Strengths perspective concedes that people will face adversity and find strategies to become resilient (Pulla,2012). A strength-based perspective values and listens to the experiences of clients in order to acknowledge existing strengths and personal resources available that may provide hope for recovery (Francis, et.al,2014). In the following instance, a social worker referred a socially isolated man living alone to a Diversional therapist for social support. The Diversional therapist conducted a bio-psychosocial assessment gathering information on his life-style history, discovering that the man loved playing the piano. The outcome of this discovery led to a man playing twice weekly for a group. The man happily practiced the piano at home to meet the responsibilities of his new engagement. As a result, this man's love of music and talent for the piano was the key to his resilience and social participation. As his capacity for recovery grew he was able to reclaim his sense of self, finding meaning, within social interactions to aid his recovery. The author's practices, informed by years of professional and practical experiences, have intentionally focussed on the innate strengths of individuals to aid in their resilience (Pulla,2012).

Both Social work and Diversional Therapy research seek to explore the social world of clients by engaging in mixed method approaches referred to as triangulation. The triangulation of research employs deductive and inductive thinking by linking quantitive data with ethnographical accounts to describe the theoretical and practical composition of human experience (Uhan, Malnar, Kurdija,2013). Social workers and Diversional therapists utilise this meld of integrated scientific research with cognitive approaches that underpin grounded theory to validate the ethnographical experiences of powerless clients (Uhan, Malnar, Kurdija,2013). Social workers in the company of other actors employ reflexive methodology as they understand the practical implications of cultural biases including the complex processes of socialisation that may enhance or impede social research. Employing mixed methodology combining quantitive and qualitative research to examine evidence-based practices thus ensuring continuous qualitative improvements (Uhan, Malnar, Kurdija,2013).

Social workers co-exist with Diversional therapists utilising recreational therapy as a tool for creative expression plus a catalyst for social change. Social workers along with Diversional therapists consciously challenge negative stereotypes the focus is on positive coping mechanisms to free the socially oppressed by aiding recovery. For example, a woman with a history of schizophrenia with an identified strength for knitting was able to participate successfully within a social group. As the planned (DT) activity enabled her to participate fully thus normalising her experience by facilitating her integration within the group (Pulla, 2012).

Diversional therapy programs are shaped and informed by the social sciences including psychology to empower the client. Facilitating individual choice and decision-making pertaining to the client's individual recreational and leisure needs (Brodsky \& Cattaneo, 2013). Person-centeredness is 
similar to Brodsky and Cattaneo's choice therapy/reality therapy as the focus is on what the client values to effect positive changes in health and wellness; thus this is the director of their recovery.

Aspects of Social work practice are similar to Diversional therapy practice as it demands a certain amount of self-disclosure plus self-presence in order to maintain a therapeutic working relationship (Knight, 2012). The challenge for the therapist is to maintain professional boundaries by limiting unnecessary personal disclosure whilst keeping the realness in practice (Knight,2012). Social workers and Diversional therapists invest heavily of the self to motivate by cultivating strategies evolved from theories to facilitate hope for self-directed transformation (Pulla,2012).

Social workers and Diversional therapists at an overarching level work together to build the individual capacity of vulnerable people. The similarities of Diversional therapy and Social work appear to be a strong desire to support, enrich and uplift the human spirit. The Strengths perspective focus is the innate capacity of people to utilise their resources to adapt survive and become resilient (Chenoweth \& McAuliffe,2008). Humans are existentially social beings that communicate via an interrelated social network of friend's family and wider social connections that make up the social hierarchy of community life. Thus, social interaction and the ability to share our own unique rich cultural and emotional histories is often the key to social and emotional well-being (Levine-Madori,2007).

Diversional therapists motivate and encourage clients to participate fully allowing for greater autonomy, choice and decision making. In art therapy, the strengths and potential of each art-work needs to be emphasised and jointly appreciated. However, the focus is not the work itself, but the value of the collective spirit that is enriched by this experience. Accordingly art's therapeutic utility correlates to theoretical strengths-based practices that underpin social work (Riggs \& Pulla, 2014). Art therapy practice is innovative imaginative and resourceful seeking to inspire creativity to encapsulate plus capitalise on it. Art therapy unlocks expressions joy, fulfilment and satisfaction that come from engaged participation thus improving outcomes for health and wellness (Riggs \& Pulla, 2014).

Diversional therapy practice and social work practice share many theoretical commonalities including the employment of universal therapeutic modalities that seek to strengthen and empower vulnerable persons (Riggs \& Pulla, 2014). Therapeutic modalities such as; art therapy, music therapy, aromatherapy, sensory activities, experiences, armchair yoga, Tai chi, meditation, or sensory gardens. Social workers \& Diversional therapists commonly work within groups to enhance the lives of vulnerable people "Group work" being the key to unlock hidden strengths. Similarly, a small group of frail aged clients many with dementia were able to work collaboratively for many weeks to produce a tile mosaic. Collaboratively working together from its inception to the end product with an observable level of intense engagement. Thus, their creativity was utilised to work together collectively employing choice and decision-making skills to carefully plus respectfully create a communal artwork; bolstering self-esteem, fostering pride and ownership of the completed mosaic. Their artistic journey provided them with a meaningful activity that purposefully increased social connectivity plus group cohesion; the completed work was framed and placed on the wall of the community centre demonstrating value and respect for the creators.

Effective group work from a Strengths-based perspective seeks to build on coping skills that are innate within individuals to enhance personal qualities that support resilience (Dawson et al., 2013). Health and Wellness is often compromised in older adults paired with co-morbidity that may necessitate the need for vulnerable persons to feel valued and socially connected. As social connection is a protective factor for those with depression (Davidson, Wingate, Rasmusen, \& Slish, 2009). Social work and Diversional therapy practice underpin the theoretical rudiments of Strengths-based practices to purposefully engage instinctive protective factors of individuals including wider mechanisms of empowerment (Pulla, 2012). Strengths-based practices facilitate positive change within the social order by encouraging resilience as opposed to focusing on deficits (Pulla, 2012).Thus, a Diversional therapist will seek to minimise embarrassment for a client who has difficulty with word finding by emphasising other known qualities or accomplishments that support the dignity of the client.

Reflections based on observations of qualitative workplace practices indicate the human capacity for social interactions to enrich and lift the human spirit. Demonstrating the strong desire and determination of an elderly client towards social connection. That drove this woman in her 100th year to work out in the hospital gym every day in order to be strong enough to return to the group. The authors suggest the benefits of social connectivity being a very necessary component to health and wellness encompassing the social, emotional and spiritual realms of human existence. Social connection is equally proportionate to individual health as is nutrition and housing. Diversional therapists seek to make a connection with the client to understand as well as anticipate the client's psychosocial and emotional needs.

Diversional therapists help to create a social environment that is inclusive and socially accepting of others. Diversional therapists support the social-emotional and physical needs of vulnerable people working towards increased health outcomes. Social work bestows a range of support mechanisms to vulnerable people via counselling, information and community linkages to bring about change. Social work is a catalyst for systemic change at the micro, meso or macro level that affects the human condition. Social work is caring, respectful, socially responsible and reflective.

Social work assists in the construction of building social 
capital within social systems, social relationships and social order. Social work assists people to build their social capital in order to gain social benefits such as information, education, housing or employment. Social capital may be accumulated at the individual level or within organisational or societal levels (Li,2011). Social workers assist vulnerable persons to navigate government regulations authoritative bodies including policies by utilising information networks or support systems (Li,2011). Limitations that may impede the growth of social capital at an organisational level includes the influence of internal policies plus external forces such as public opinion posing structural barriers to social work (Li,2011).

Thus, social workers often are subjected to organisational policies aimed at protecting the organisations reputation which reflects the expectations of public opinion rather than the needs of clients (Li,2011). Diversional Therapists may also be subject to organisational barriers that limit or impede therapeutic activities; obstacles may include insufficient staff, funding or understanding of the value of psychosocial therapy.

Diversional Therapy delivers emotionally sensitive care via personalised activities that aim to improve life quality by enhancing mood and behaviours (O'Conner, Ames Gardner \& King, 2009). Diversional Therapy is proven to be most effective in the delivery of psychosocial interventions. That may relieve the symptoms of anxiety, depression and agitation in vulnerable persons such as those with dementia (O'Conner et al., 2009). A woman with dementia plus aphasia was observed to hold a conversation whilst engaged in a painting activity. Unaware as she was able to describe her walks in the forest when she was a girl such is the power of creative engagement. Emotion sensitive care recognises the social and emotional needs of others. Such as the placing a woman with an intellectual disability, who had recently lost her mother, into a group of elderly women, to alleviate her emotional pain.

Diversional therapy assists in a multiplicity of ways and is complimentary to other disciplines such as social work due to the overlap of theory and functions (Buettner \& Legg, 2011). Complimentary participation is encouraged as there is much overlap between the two professions. Observed at the micro level, with differences located at the macro and meso levels despite the fact that both professions seek to achieve comparable outcomes for vulnerable persons.

Diversional therapy works directly by "being in the moment" with the client whilst Social Work seeks to change embedded societal and organisational structures that adversely affect at-risk individuals (Buettner \& Legg, 2011). Diversional therapy programs assist with creating an engaging environment to support persons with a wide range of physical and psychosocial diagnosis presenting the opportunity for co-treatment with other disciplines (Buettner \& Legg, 20011).

Social work and Diversional therapy favour a person-centered philosophy seeking to assist those at risk to discover personal strengths to aid coping and resilience. As a result, both disciplines work together to utilise theories of human behaviour together with an understanding of social systems to support and enhance well-being of others. Social work via a social justice framework challenges the negative stereotypes associated with gender, sexuality, ageism, race, culture and employment which are socially and culturally embedded (AASW, 2013).

Diversional Therapy is complimentary to the processes of change as is social work, with both disciplines accountable for timely efficient and effective delivery of services. Documentation demonstrates the effectiveness of service delivery with accountability beginning with the initial program design, continuing throughout service delivery and ultimate evaluation process (Stumbo, 2001). Social work is equally committed to these principles. Resilience in ageing may be assisted by psychosocial interventions to promote healthy ageing by lessening the emphasis on disability and loss focussing on the promotion of positive aging from a strengths-based perspective (Ford, 2005). Thus, the two professions have coalesced theories, values and practices to actively challenge wrongful assumptions of ageing respecting the realities, by mobilising therapeutic interventions to improve the human condition (Ford,2005).

\section{Conclusion}

In conclusion, the authors of this paper argue that Social work and Diversional therapy co-exist due to commonalities in person-centered strengths-based philosophy. Overlapping with social consciousness emanating from a social justice framework that is ethical, respectful and caring; whilst working to achieve the best possible levels of personal and social wellbeing for all clients (AASW,2010). The authors make similar assumptions based on years of practice that pertains to the co-existing values of social work and Diversional therapy. These assumptions strengthened by observable, positive, outcomes result from workplace practice together with qualitative and ethnographical accounts from vulnerable clients that typify a person-centered and strengths-based philosophy.

Diversional therapy and social work both have a desire to support the client to investigate and define their story, build resilience, build social capital and enrich the personal experience of self. Strength-based practice gives the Diversional therapist and social worker a common proven approach to underpin practice. This approach allows the Diversional therapist and social worker to support the client's new understanding of self, by assisting the client to employ their strengths, capabilities and resources to overcome adversity and reach for goals. The assessment process, which is respectful, responsive and flexible to the client's needs, understands that many different forms of communication can be used to develop a therapeutic relationship. By advocating and assisting clients Diversional 
therapy and Social work can have an impact on building supportive communities, challenging assumptions and negative stereotypes, opposing social structures that oppress vulnerable people, and encourage social change. Strength-based practice facilitates positive change by encouraging resilience in an ethical, respectful and caring manner to achieve the best possible levels of personal and social well-being for all clients.

\section{REFERENCES}

AASW-Australian Association of Social Workers. (2014, August 30). AASW is the professional body for social workers.-AASW-Australian Association of Social Workers Association Online by IVT. Retrieved from http://www.aasw.asn.au/

Australian Association of Social Work. (2013, October 31). Australian Association of Social Work, AASW, Code of Ethics. Retrieved from http://www.aasw.asn.au/document/item/1201

Brodsky, A. E., \& Cattaneo, L. B. (2013). A transconceptual model of empowerment and resilience: Divergence, convergence and interactions in kindred community concepts. American journal of community psychology,52(3-4), 333-346.

Buettner, L., \& Legg, T. (2011). Recreation Therapy and MDS 3.0. Term Living, 60(8), 38-41. Retrieved from http://search.proquest.com/docview/898808627?accountid=10344

Chenoweth, L. I., \& McAuliffe, D. A. (2012). The road to social work $\&$ human service practice: An introductory text (3rd ed.). Melbourne, Vic: Cengage Learning.

Cornwell, B., Laumann, E. O., \& Schumm, L. P. (2008). The social Connectedness of Older Adults. A National Profile. American Sociological Review, 73(2), 185-203. Retrieved from http://www.aasw.asn.au/document/item/1201 AASW, Code of Ethics $(2010$

Crow, B. (2007). Inequalities of the world: New Theoretical Frameworks, Multiple Empirical Approaches. Contemporary Sociology, 36(4), 388-390. Retrieved from $\mathrm{http} / /$ search.proquest.com/docview/233596437?accountid=10344

Dawson, N. T., Powers, S. M., Krestar, M., Yarry, S. J., \& Judge, K. S. (2013). Predictors of self-reported psychosocial outcomes In individuals with dementia. The Gerontologist, 53(5), 748.

Davidson, C. L., Wingate, L. R., Rasmussen, K. A., \& Slish, M. L. (2009). Hope as a predictor of interpersonal suicide risk. Suicide and Life-Threatening Behavior, 39(5), 499-507.

Diversional Therapy Australia. (2014). Retrieved from http://diversionaltherapy.org.au/

Dowling, J. R. (1995). Keeping busy: A handbook of activities for persons with dementia.. Baltimore, USA: John Hopkins University Press.

Ford, S. (2005). Resilience in older age. In Psych, 27(2). Retrieved from http:www.psycho.ogy.org.au/publications/in-psych/resilience

Fossey, E., Harvey, C., Mokhtari, M. R., \& Meadows, G. N. (2012). Self-rated assessment of needs for mental health care: A qualitative analysis. Community Mental Health Journal, 48(4), 407-19. Retrieved from http://dx.doi.org/10.1007/s10597-011-9433-6
Francis, A. P., Pulla, V., Clark, M., Mariscal, S., \& Ponnuswami, I. (2014). Advancing Social Work in Mental Health through Strengths-Based Practice. Brisbane: Primrose Hall Publishing Group.

Healy, K. (2005). Social work theories in context: Creating frameworks for practice. Houndmills, Basingstoke: Palgrave Macmillan.

Knight, J. (2012). "Robust professional back-up: Jenny Knight investigates a clinical supervision scheme designed to support and develop the skills of nurses who specialise in community dementia care." Nursing Standard 26(30): 61.

Levine-Madori, L. (2007). Therapeutic Thematic Arts Programming for older adults. Baltimore Maryland, USA: Health Profession Press.

Li, Z. (2011). Social Capital and public image of non-profit organizations. International Journal of Business and Social Science, 2(13). Retrieved from http://search.proquest.com/docview/898808 627? accountid $=10344$

Moody, E., \& Phinney, A. (2012). A community-engaged art program for older people:Fostering social inclusion. Canadian Journal on Aging, 31(1), 55-64. Retrieved from http://dx.doi.org/10.1017/S0714980811000596

Morris-Kay, G. M. (2010). The Evolution of Human Artistic Creativity. Journal of Anatomy 216. 158-176 doi:10.1111/j.1469-7580.2009.01160.x

Noonan, J. (2011). Life value and social justice. Studies in Social Justice 5(1), 1-n/a. Retrieved from http://search.proquest.com/docview/1315917502?accountid=1034 4

O'Connor, D. W., Ames, D., Gardner, B., \& King, M. (2009). Psychosocial treatments of psychological symptoms in dementia: A systematic review of reports meeting quality standards. International Psycho-geriatrics 21(2), 241-51. Retrieved from http:dx.doi.org/10.1017/S1041610208008223

Pulla, V. (2012). What are Strengths Based Practices all about? In V. Pulla, L. Chenoweth, A. Francis and S. Bakaj (Eds.), Papers in Strength based practice. Delhi: Allied Publishers Pty Ltd.

Riggs, A., \& Pulla, V. (2014). Visual and Theatre Arts and Community Development. In K. Goel, V. Pulla, \& A. Francis (Eds.), Community Work: Theories, Experiences \& Challenges, 30-47. Bangalore, India: Niruta Publications.

Stumbo, N. J., \& Peterson, C. A. (2001). Professional issues in therapeutic recreation: On competence and outcomes. (4th ed.). Illinois State University, USA: Pearson Benjamin Cummings.

Uhan, S., Malnar, B., \& Kurdija, S. (2013). Grounded Theory and Inductive Ethnography:. A Sensible Merging or a failed encounter? Teorija in Praksa. 50(3), 642-657,689. Retrieved from http://search.proquest.com/docview/1442725186?accountid=1034 4

Walther, S., \& Fox, H., (2012). Narrative therapy and outsider witness practice: Teachers as a community of acknowledgement. Educational \& Child Psychology 29(2), 8-17

Wartel, S. G. (2003). A strengths-based practice model: Psychology of mind and health realization. Families in Society, 84(2), 185. Retrieved from http://search.proquest.com/docview/230158773?ac countid $=10344$ 